Tropical Journal of Pharmaceutical Research November 2016; 15 (11): 2483-2488

ISSN: $1596-5996$ (print); 1596-9827 (electronic)

(C) Pharmacotherapy Group, Faculty of Pharmacy, University of Benin, Benin City, 300001 Nigeria.

All rights reserved.

Available online at http://www.tjpr.org

Original Research Article

http://dx.doi.org/10.4314/tjpr.v15i11.25

\title{
Assessment of anxiety and depression in hospitalized cardiac patients of Faisalabad Institute of Cardiology, Pakistan
}

\author{
Shujaat Ali Khan ${ }^{1}$, Saira Azhar ${ }^{1 *}$, Sara Marriam Asad ${ }^{1}$, Ayesha Iqbal ${ }^{1}$, Rozina \\ Kousar ${ }^{1}$, Mahmood Ahmad ${ }^{2}$, Asia Taha ${ }^{3}$, Ghulam Murtaza ${ }^{1}$ \\ ${ }^{1}$ Department of Pharmacy, COMSATS Institute of Information Technology, Abbottabad, ${ }^{2}$ Faculty of Pharmacy, The Islamia \\ University of Bahawalpur, Bahawalpur, Pakistan, ${ }^{3}$ College of Clinical Pharmacy, King Faisal University, Al ahsa, Saudi Arabia \\ *For correspondence: Email: drsairaazhar@ciit.net.pk; Tel: 00923142082826; Fax: 0092992383441
}

Received: 7 January 2016

Revised accepted: 29 September 2016

\begin{abstract}
Purpose: To assess the level of anxiety and depression in hospitalized cardiac patients in Faisalabad Institute of Cardiology, Faisalabad, Pakistan.

Methods: The study was conducted on hospitalized cardiac patients at Faisalabad Institute of Cardiology (FIC), Faisalabad. Aga Khan University Anxiety and Depression Scale (AKUADS) was applied to estimate the occurrence of depression and anxiety in selected participants. This study involved 400 diagnosed hospitalized cardiac patients and another 400 participants without cardiac disease as control group.

Results: The anxiety and depression level in hospitalized cardiac patient's was $79.5 \%$ (318), compared with $68.25 \%$ (273) of the control group. Female patients were also more prone to depression than male patients. Psychological suffering was 1.80 times more in the hospitalized cardiac patients $(O R=1.804$, $95 \% \mathrm{Cl}=1.308-2.488, p=0.0001)$. The results showed that gender was the leading factor in the occurrence of co-morbidities such as depression and anxiety.

Conclusion: Depression symptoms are more common among hospitalized patients than in those without cardiac disease. Close monitoring is required and patients with psychiatric illness should be referred for appropriate treatment to overcome this risk.
\end{abstract}

Keywords: Hypertension, Anxiety, Depression, Gender, Cardiac patients

Tropical Journal of Pharmaceutical Research is indexed by Science Citation Index (SciSearch), Scopus, International Pharmaceutical Abstract, Chemical Abstracts, Embase, Index Copernicus, EBSCO, African Index Medicus, JournalSeek, Journal Citation Reports/Science Edition, Directory of Open Access Journals (DOAJ), African Journal Online, Bioline International, Open-J-Gate and Pharmacy Abstracts

\section{INTRODUCTION}

Cardiovascular diseases (CVDs) are one of the prime contributors of global burden of disease (BOD). In 2008, it was reported that due to CVDs 17.3 million people died. One of the leading contributor of this disease is depression, which represent four of the 10 leading causes of disability worldwide and make up $12 \%$ of the global burden of disease [1]. Depression and anxiety are very common among patients having cardiac problems, and in a study involving patients above 30,000 , it was reported that $9.3 \%$ ambulatory cardiac patients showed depression while control showed $4.8 \%[2,3,4]$. It is important to detect and treat depression in Coronary Artery Disease (CAD) and post-MI patients, as the risk of a cardiac event doubles within 1 to 2 years after an MI [5,6].

In heart failure patients, certain symptoms such as exhaustion, loss of hunger, feeling of 
tiredness and sleeplessness are common $[7,8]$. One study indicates that hospitalized elderly patients show $41 \%$ depressive symptoms with heart failure, and it is comparable to another study which reported $14-77 \%$ [9]. In a few North American general hospitals, up to $5 \%$ of all admissions are referred to a psychiatrist [10]. Research had been conducted on patients' depression levels but there are still substantial gaps in the literature on this subject. Moreover, there is a dearth of literature on psychological illness in hospitalized cardiac patients.

The main focus of the present study was to determine the incidence of anxiety and depression among hospitalized cardiac patients using a dependable and valid instrument.

\section{METHODS}

\section{Study design}

Ethical approval for the study was obtained from Ethics Review Committee of Fasilabad Institute of Cardiology (FIC), Fasilabad, Pakistan (approval reference no. CIIT 2011/FIC 2011-28MS 13). Ethical principles for medical research involving human subjects were adopted for this study in accordance with the Declaration of Helsinki [11].

The study was a cross-sectional study conducted in Faisalabad Institute of Cardiology (FIC), a 202bed hospital serving cardiac patients in the region of Faisalabad. Patients were included from surgery ward, cardiac ward, ICU unit I and unit II, angiography ward and emergency department, to find out the incidence of anxiety and depression in hospitalized patient. Patients visiting the cardiac department clinic, were also included in the study. However, patients who had appointment with a psychiatrist and/or were medically unstable, suffering from illnesses other than cardiac disease, or psychiatric illnesses such as hallucinations and dementia, were excluded from the study. Age range for this study was 20 to 80 years. Patients showing willingness to complete the questionnaire and had given their consent were included in this research. Those in the control group were arbitrarily selected from the community the hospital located in. Every one in three persons visiting the hospital was enrolled in this study after confirming willingness to participate.

The study instrument was a valid questionnaire which was completed by the participants after a detailed interview. The data obtained include the demographical characteristics of the participants, including education, monthly salary and residence. Type of disease and other surgical related information were collected from patient medical records. Medical history of cardiovascular diagnosis which included congestive cardiac failure (CCF), acute myocardial infarction (AMI), left ventricular failure (LVF), coronary artery disease (CAD) and rheumatic heart disease (RHD) were obtained from the medical records of each patient.

To determine the relationship of anxiety and depression with life style, information on smoking history and physical activity detail were also obtained. Nervousness and depression among hospitalized cardiac patients were measured by a valid scale, Aga Khan University Anxiety and Depression Scale (AKUADS). It contains 25 items and is basically used to measure the occurrence of anxiety and depression among admitted patients. It is a reliable and valid instrument to measure the level of psychological distress in hospitalized patients and commonly used in Urdu. It reveals a sensitivity of $66 \%$ and a specificity of about $79 \%$; it indicates a positive value of 83 , and 60 shows a negative value at a cut-off score of 20 [12]. It shows a high level quality of reliability and a final conclusion explained item-item correlation $\geq 0.75$. After a cut-off point, the data obtained were entered categorically from the questionnaire.

\section{Data analysis}

The data were computed and analyzed using Statistical Package for Social Sciences (version 15). Descriptive analysis was carried out as applicable, and each item in the questionnaire reported as percentage and frequencies Logistic regression analysis was done with regard to clinical, behavioral and demographical factors. Statistical significance was set at $p<0.05$.

\section{RESULTS}

Out of the initial 500 hospitalized cardiac patients earmarked for this study, 400 were selected because 100 patients were not eligible for this survey as 20 of them were on psychiatric treatment, 30 showed serious medical illness, 10 incomplete medical records, 15 language problems, and 25 were unable to respond. At majority of the hospitalized patients were in the age range of $40-60$ years $(53.2 \%)$, male $(53.0$ $\%)$, from urban residency $(69.0 \%)$, illiterate $(47.5$ $\%)$, married $(95.2 \%)$, house wife $(42.8 \%)$, monthly income 5000 (51.2 \%). Maximum number of patients were non-smoker $(67.0 \%)$ and showing exercise time less than $20 \mathrm{~min}$ 
Table 1: Demographics of study groups

\begin{tabular}{|c|c|c|}
\hline Variable & $\begin{array}{c}\text { Cardiac } \\
\text { patients, } \\
\mathrm{N}(\%) \\
\end{array}$ & $\begin{array}{c}\text { Control, } \\
\text { N (\%) }\end{array}$ \\
\hline \multicolumn{3}{|l|}{ Age } \\
\hline $20-40$ years & $102(25.5)$ & $230(57.5)$ \\
\hline $40-60$ years & 213(53.2) & 158(39.5) \\
\hline$<60$ years & $85(21.2)$ & $12(3.0)$ \\
\hline \multicolumn{3}{|l|}{ Gender } \\
\hline Male & $212(53.0)$ & $207(51.8)$ \\
\hline Female & $188(47.0)$ & $193(48.2)$ \\
\hline \multicolumn{3}{|l|}{ Marital status } \\
\hline Unmarried & $19(4.8)$ & $58(14.5)$ \\
\hline Married & $381(95.2)$ & $342(85.5)$ \\
\hline \multicolumn{3}{|l|}{ Locality } \\
\hline Urban & $276(69.0)$ & $288(72.0)$ \\
\hline Semi-urban & $49(12.2)$ & $13(3.2)$ \\
\hline Rural & $75(18.8)$ & $99(24.8)$ \\
\hline \multicolumn{3}{|l|}{ Education } \\
\hline Illiterate & $190(47.5)$ & $266(66.5)$ \\
\hline Primary & $66(16.5)$ & $99(24.8)$ \\
\hline Matriculation & $116(29.0)$ & $26(6.5)$ \\
\hline Intermediate & $8(2.0)$ & $3(0.8)$ \\
\hline Graduation & $9(2.2)$ & $3(0.8)$ \\
\hline Master & $11(2.8)$ & $3(0.8)$ \\
\hline \multicolumn{3}{|c|}{ Occupational status } \\
\hline Private service & $81(20.2)$ & $143(35.8)$ \\
\hline Govt. service & $31(7.8)$ & $54(13.5)$ \\
\hline House wife & $171(42.8)$ & $162(40.5)$ \\
\hline Jobless & $105(26.2)$ & 13(3.2) \\
\hline student & $12(3.0)$ & $28(7.0)$ \\
\hline \multicolumn{3}{|l|}{ Income } \\
\hline 5000 & $205(51.2)$ & $315(78.8)$ \\
\hline $5,000-10,000$ & $179(44.8)$ & $75(18.8)$ \\
\hline $10,000-20,000$ & $16(4.0)$ & $10(2.5)$ \\
\hline \multicolumn{3}{|c|}{ Physical exercise } \\
\hline$>20 \mathrm{~min}$ & $208(52.0)$ & $18(4.5)$ \\
\hline 20-40min & 156(39.0) & $173(43.2)$ \\
\hline $40-60 \mathrm{~min}$ & $24(6.0)$ & $167(41.8)$ \\
\hline$<60 \mathrm{~min}$ & $12(3.0)$ & $42(10.5)$ \\
\hline \multicolumn{3}{|l|}{ Smoking } \\
\hline Yes & $15(3.8)$ & $22(5.5)$ \\
\hline Current & $3(0.8)$ & $41(10.2)$ \\
\hline Ex-smoker & $114(28.5)$ & $122(30.5)$ \\
\hline no & $268(67.0)$ & 215(53.8) \\
\hline Heart attack & $151(37.8)$ & \\
\hline \multicolumn{3}{|c|}{ Add salt to food } \\
\hline Never & $40(10.0)$ & \\
\hline Occasionally & $355(88.8)$ & \\
\hline Always & $5(1.2)$ & \\
\hline \multicolumn{3}{|l|}{ Dietary habit } \\
\hline Red meat & $3(0.8)$ & \\
\hline White meat & $177(44.2)$ & \\
\hline Vegetables & $220(55.0)$ & \\
\hline \multicolumn{3}{|l|}{ Heart disease } \\
\hline $\mathrm{CHF}$ & $151(37.8)$ & \\
\hline AMI & $99(24.8)$ & \\
\hline LVF & $80(20.0)$ & \\
\hline CAD & $46(11.5)$ & \\
\hline RHD & $24(6.0)$ & \\
\hline
\end{tabular}

(52.0\%). congestive cardiac failure (37.8\%), acute myocardial infarction (24.8\%), left ventricular failure $(20.0 \%)$, coronary artery disease $(11.5 \%)$ and rheumatic heart disease $(6.0 \%)$ were the leading diagnosis among the hospitalized cardiac patients. 400 individuals were prefer for this study from a collection of 460 individuals selected as a control group for this research, with a response rate of $86.95 \%$. Table 1 , explains the demographical details of control group and also with the clinical data and demographics features of hospitalized cardiac patients was accomplished.

By using cut-off score of 20 on AKUADS, on the whole $79.5 \%$ (318) admitted cardiac patients were commonly noticed depression and fretfulness as compare to the control group showing $68.25 \%(273)$ anxiety and nervousness. $P$-value show a significant level $<0.001$, and the difference among the incidence rate was observed statistically. Hospitalized patients shows 1.80 times more psychological distress $(95 \% \mathrm{Cl}=1.308-2.488)$. Congestive cardiac failure, acute myocardial infarction, left ventricular failure, coronary artery disease and rheumatic heart disease show high incidence of anxiety and depression.

Logistic regression analysis results were described in Table 2 (a) and Table 2 (b) which reveals the outcomes of depression and anxiety in hospitalized patients related their clinical, behavioral and demographical features. Discussion about result analysis shows that females drastically increase the risk of depression and anxiety among hospitalized patients as compared to males. It has been observed that there is no significant relation among psychological distress and demographical features like, age, occupation, marital status, education, residence, and socioeconomic status. Probability of having fretfulness and anxiety in not significantly persuade by cardiovascular diseases. Overall physical exertion and habit of smoking did not affect the occurrence of depression and anxiety.

\section{DISCUSSION}

Presence of high occurrence of depression and anxiety in hospitalized cardiac patients as contrast with control group is one of the major finding of this research. Admitted cardiac patients had fretfulness and depression which is much higher result as compared to previous studies showing $60 \%$ depression [13] and some studies reported $48 \%$ fretfulness among hospitalized heart failure patients. Studies where small 
Table 2: Logistic regression analysis data for psychological illness in hospitalized cardiac patients

\begin{tabular}{|c|c|c|c|}
\hline Variable & OR & $95 \% \mathrm{Cl}$ & $P$-value \\
\hline Age & & & 0.2916 \\
\hline $20-40$ years & 1.868 & & 0.028 \\
\hline $40-60$ years & 2.824 & & 0.000 \\
\hline$<60$ years & 1.135 & $1.064-3.280$ & 0.847 \\
\hline Gender & & & 0.0295 \\
\hline Male & 1.517 & & 0.058 \\
\hline Female & 2.253 & $0.985-1.567$ & 0.001 \\
\hline Marital status & & & 0.369 \\
\hline Unmarried & 0.825 & & 0.738 \\
\hline Married & 2.254 & $0.268-2.544$ & 0.000 \\
\hline Locality & & & 0.404 \\
\hline Urban & 2.215 & & 0.000 \\
\hline Semi-Urban & 1.007 & & 0.991 \\
\hline Rural & 1.504 & $1.483-3.306$ & 0.222 \\
\hline Education & & & 0.445 \\
\hline Illiterate & 2.239 & & 0.000 \\
\hline Primary & 1.237 & & 0.564 \\
\hline Matriculation & 0.785 & & 0.655 \\
\hline Intermediate & 14.000 & & 0.72 \\
\hline Graduation & 1.750 & & 0.7000 \\
\hline Master & 20.000 & $1.414-3.548$ & 0.031 \\
\hline Occupational status & & & 0.4104 \\
\hline Private sector & 1.747 & & 0.092 \\
\hline Govt/public sector & 1.029 & & 0.954 \\
\hline Housewife & 2.636 & & 0.000 \\
\hline Jobless & 2.476 & & 0.121 \\
\hline Student & 1.111 & $0.909-3.358$ & 0.885 \\
\hline Income & & & 0.066 \\
\hline$<5000$ & 1.589 & & 0.023 \\
\hline $5,000-10,000$ & 1.786 & & 0.070 \\
\hline $10,000-20,000$ & 4.667 & $1.030-2.370$ & 0.105 \\
\hline Physical exercise & & & 0.176 \\
\hline$<20 \mathrm{~min}$ & 4.659 & & 0.001 \\
\hline 20-40min & 2.378 & & 0.001 \\
\hline 40-60min & 1.282 & & 0.619 \\
\hline$>60 \mathrm{~min}$ & 0.320 & $1.736-12.507$ & 0.083 \\
\hline Smoking & & & 0.304 \\
\hline Yes & 0.952 & & 0.942 \\
\hline Current & 0.232 & & 0.218 \\
\hline Ex-smoker & 1.790 & & 0.054 \\
\hline No & 1.889 & $0.445-2.123$ & 0.003 \\
\hline Dietary habit & & & 0.330 \\
\hline Red meat & 0.923 & & 0.952 \\
\hline White meat & 2.261 & & 0.001 \\
\hline Vegetables & 1.601 & $0.069-12.280$ & 0.039 \\
\hline Cardiac disease & & & 0.127 \\
\hline Congestive cardiac failure & & & 0.049 \\
\hline Acute myocardial infarction & 1.542 & & 0.008 \\
\hline Left ventricular failure & & & 0.020 \\
\hline Coronary artery disease & 2.093 & & 0.003 \\
\hline \multirow[t]{3}{*}{ Rheumatic heart disease } & 2.016 & $1.000-2.376$ & 0.558 \\
\hline & 3.815 & & \\
\hline & 0.775 & & \\
\hline
\end{tabular}

number of patients were taken, reported depression rate between 13 and $42 \%$ [14].

Psychiatric distress, mental illness and problems like depression and anxiety are there in every field of medicine [15]. Particularly in Pakistan recent survey reported that incidence of depression in our general population come in the range from 25 to $66 \%$ among females, which is more than in males (10 to $25 \%$ ) [16].

In this present study, it comes to know that females $(\mathrm{OR}=2.253$ ) were more prone towards depression and nervousness as compared to males $(O R=1.517)$. Same results were presented in some other studies that concluded the same fact that females (64\%) were observed 
of having more odds of suffering from depression than males (44\%).previous studies also observed that women were diagnosed twice time more depressed in contrast with males among hospitalized cardiac patients. Another study also concluded that female gender were 1.68 times more prone to have psychological distress $(\mathrm{OR}=$ $1.68,95 \% \mathrm{Cl}=1.14-2.48)$.

It is very important to identify after such type of researches that why depression prevails among majority of the admitted cardiac patients in hospitals. Some researchers found that cardiac patients were suffering from depression because of high readmission rate in hospital. Rate of mortality is higher in patient having cardiac disease as well as depression as compared to those individuals suffering from only heart diseases.

Number of reasons accounts the association of cardiac disease with fretfulness and depression. Mentally distress individuals showing awkward behaviors like; smoking, having alcohol, taking unhygienic and unhealthy food. Other features which may include personality disorder like aggression may be related with cardiovascular diseases and depression. Many life time events also correlate the link of cardiac arrest and depression. Having low socioeconomic background may enhances the symptoms of depression. State of mental strain develop when individual remain in long term stressful environment which escort to mental fatigue. Reactivity of Cortisol is observed during unfavorable and offensive circumstances. Depression can also causes other physiological and biochemical changes like bradycardia, myocardial ischemia and ventricular instability.

Question arises from this research that why prevalence of anxiety and psychological illness rate is higher among hospitalized patients and non-cardiac individuals? The reason may be because Presence of mental stress among cardiac patients in developed countries was studied more as compared to the developing countries. In this study, a majority of the participants belongs to low socioeconomic status, illiterate, and unemployed. Current condition of Pakistan puts them at high level of threat as we are still suffering from economic crisis, unemployment and socio-political instability. Through the amendment of previous studies on the same topic, we had carried out study on hospitalized cardiac patients and patient having no cardiac disease and analyzed the effect of anxiety and depression on cardiac diseases by using an instrument which is valid and reliable. This study observed a dominant linkage associated with gender and anxiety. Females were more inclined towards depression as compared to males.

Statistically no significant relation was observed between anxiety, depression and demographic features that were involved in this study. Education, monthly income, marital status, present occupation and locality did not show any prominent influence on mental illness in our research. Our research is strengthened by having standardized measures, estimation of various variables that may influence the incidence of anxiety and fretfulness with a good rate of response from participants, and above all having a control group of non-cardiac individuals to compare with hospitalized cardiac patients. A range of admitted cardiac cases and control cases were carried out with having no differences in their socioeconomic status and result was analyzed through same instrument.

For the management of mental illness and psychological distress, it is important to focus on the recognition of symptoms and increase awareness about the occurrence of psychological morbidity. Complete screening and reliable psychological test of hospitalized cardiac patient must be done as a part of standard care. Cardiologist must refer the patients, on the basis of their psychological test results.

\section{Limitations of the study}

The results reported in this study were subjected to some limitations, like there was no facilitation for diagnosis of control group. The study was conducted in only one hospital of Faisalabad so data cannot be generalized to other cardiac hospitals.

\section{CONCLUSION}

The incidence of generalized anxiety and depressive disorder was estimated as $79.5 \%$ among hospitalized cardiac patients in Faisalabad. The findings of this study also indicate that symptoms of depression are more common among hospitalized cardiac patients than in persons without cardiac disease, and that female cardiac patients are more like to suffer depression than male cardiac patients. Close monitoring is required to ensure that patients with symptoms of depression are referred for appropriate treatment. Greater efforts are needed to identify and treat anxiety in outpatients attending cardiology clinics.

Trop J Pharm Res, November 2016; 15(11): 2487 


\section{DECLARATIONS}

\section{Acknowledgement}

The authors appreciate the assistance and cooperation of the staff of FIC. The authors are also grateful to COMSATS for the opportunity to undertake this study.

\section{Conflict of Interest}

No conflict of interest associated with this work.

\section{Contribution of Authors}

The authors declare that this work was done by the authors named in this article and all liabilities pertaining to claims relating to the content of this article will be borne by them.

\section{Open Access}

This is an Open Access article distributed under the terms of the Creative Commons Attribution License, which permits unrestricted use, distribution, and reproduction in any medium, provided the original work is properly credited.

\section{REFERENCES}

1. WHO. Mental health: a call for action by world health ministers. Geneva: World Health Organization, 2001.

2. Egede LE. Major depression in individuals with chronic medical disorders: prevalence, correlates and association with health resource utilization, lost productivity and functional disability. Gen Hosp Psychiat 2007; 29: 409-416.

3. Mitka M. Routine depression screening advised for patients with coronary heart disease. JAMA 2008; 300 : 2356-2357.

4. De Jonge OP, Johan $V$, Van-melle HS, Joost $P S$, Titia AK, Astrid VV, Dirk JV, Maarten PH, Harry JGM \& Aart. (2006). Symptom dimensions of depression following myocardial infarction and their relationship with somatic health status and cardiovascular prognosis. Am. J. Psych 2006; 163: 138-144.

5. Barth J, Schumacher M, Herrmann LC. Depression as a Risk Factor for Mortality in Patients with Coronary Heart
Disease: A Meta-analysis. Psychosom. Med 2004; 66: 802-813.

6. Steffens DC, Jiang CM, Pieper WJ, Kuchibhatla CF, Arias MN, Look RM, Davenport A, Gonzalez C, Krishnan MB. The effect of major depression on functional status in patients with coronary artery disease. Curr Opin Cardiol. 2006; 21: 319-322.

7. Thombs Brett DJ, Peter C, James CW, Mary AF, Nancy M, Alex JZ, Chete L, Bruno BS, Cheri GS \& Karl Z. Depression screening and patient outcomes in cardiovascular care: a systematic review. JAMA 2008; 300: 2161-2171.

8. APA. Diagnostic and Statistical Manual of Mental Disorders, 4th edn, Text Revision, American Psychiatric Association; 2000.

9. Lesman-Leegte IJ, Tiny S, Robert L, Gerard V, Dirk J. Depressive symptoms are prominent among elderly hospitalised heart failure patients. Eur J Heart Fail 2006; 8: 634-640

10. Huyse FJ, Lobo T, Malt A, Opmeer BC, Stein BC, Creed $B$, Crespo F, Gardoso MD., Guimaraes G, Mayou R, Moffaert V, Rigatelli M, Sakkas $P$, Tienari P. European Consultation-Liaison Psychiatric Services: The ECLW Collaborative Study. Acta Psychiatr. Neurol. Scand 2000; 101: 360-366.

11. The World Medical Association Declaration of Helsinki Recommendations guiding physicians in biomedical research involving human subjects [online publication]. Revised October 2000. http://www.wma.net/e/policy /b3.html (accessed 4 August 2006).

12. Ahmer S, Faruqui RA, Aijaz A. Psychiatric rating scales in Urdu: a systematic review. BMC Psychiatry 2007; 7: 59.

13. Hussain, Tabish S, Xiang S, Adji T, Tajammul A, Sara. Depression among Congestive Heart Failure Patients: Results of a Survey from Central China. JPMS 2011; 1 : 38-42.

14. Murberg TA., Bru E. Long-term effect of social relationships on mortality in patients with congestive heart failure. J Psychosom Res 2001; 51: 207-217.

15. Ruddy $R$, House A. A standard liaison psychiatry service structure? A study of the liaison psychiatry services within six strategic health authorities. Psychiatric Bulletin. 2003; 27: 457-460.

16. Mumford, Minhas DB, Akhtar FA, Akhtar I, Mubbashar $\mathrm{MH}$. Stress and psychiatric disorder in urban Rawalpindi. A community survey. Br J Psychiatry 2000; 177: 557-562. 